\title{
Evaluation of Road Traffic Accidents in Moyale Town, Oromia Regional State, Ethiopia
}

\author{
Aliyi Mama Gasu \\ Department of Environmental Science, College of Natural and Computational Science, Madda Walabu University, Robe Bale, Ethiopia \\ Email address: \\ aliyimama56@gmail.com

\section{To cite this article:} \\ Aliyi Mama Gasu. Evaluation of Road Traffic Accidents in Moyale Town, Oromia Regional State, Ethiopia. International Journal of \\ Transportation Engineering and Technology. Vol. 5, No. 1, 2019, pp. 1-10. doi: 10.11648/j.ijtet.20190501.11
}

Received: February 13, 2019; Accepted: March 18, 2019; Published: April 12, 2019

\begin{abstract}
Road traffic accidents are the major but neglected public health challenges that worsen public health and development if effective steps are not taken to curb it. Therefore the aim of this study was to assess and describe the patterns and associated causes of road traffic accidents in the Case of Moyale, Oromia Regional State. A cross-sectional study was conducted during 0ctober and November 2016. The study sample was composed of 191respondents systematically selected from households and 20 interviewees purposively selected from drivers and government officials. The study employed a descriptive survey design by using self-administered questionnaires face-to-face interview and document analysis. The research was also conducted based on the archive of traffic police data between 2012 and 2016. Results indicated that road traffic accident is a serious problem in the town of Moyale. The numbers have been following an increasing trend throughout the study period and the rate of increase has been rising rapidly due to high population number and high traffic mixes. The number and density of road traffic accidents occurring on the main roads were very high with figure ranging $80-90 \%$ of the total. Mixed allocation of land use type, high volume of traffic flow, poor nature of the road, lack of road facilities, poor traffic management and low level of enforcement contribute to these problems. In the study, pedestrians and motor cyclists are the most affected road users. The risks are higher among males, particularly those who are economically active age group. All safety measures introduced to protect the road users are disregarded by the large proportion of stakeholders. The study recommends that Moyale town needs to adjust human behavior to the traffic stream and fixed facilities to contrive ways and means of better traffic accommodation.
\end{abstract}

Keywords: Causes and Vulnerability, Pedestrians, Road Traffic Accidents

\section{Introduction}

Road traffic accidents are the major but neglected public health challenges. Road traffic accident (RTA) is defined as a collision or incident involving at least one road vehicle in motion that can be on a public or private road to which the public have the right of access. Thus, RTA can be a collision among vehicles, between vehicles and pedestrians, between vehicles and animals, or between vehicles and geographical or architectural obstacles [1].

Road traffic accidents are a global problem affecting all sectors of society. To date, road safety has received insufficient attention at the national and regional levels. This has resulted in part from: a lack of information on the magnitude of the problem and its preventability; a fatalistic approach to road crashes; and a lack of the political responsibility and multidisciplinary collaboration needed to tackle it effectively. However, Road traffic accidents occur as a result of several factors associated with the traffic system, namely: road users, road environment and vehicles. Despite having low road network density and vehicle ownership, Ethiopia has relatively high accident records [2].

Various studies done on road traffic accidents in Ethiopia have shown the escalation of the problem at the national level. Road traffic injury is high in Ethiopia, at least 70 people die for every 10,000 vehicle accidents annually [3].

According to Road Transport Authority report, 1,800 people died and 7,000 injured in 2003 across the country [4]. In $2007 / 8$, a total of 15,082 accidents occurred in the country. Of them the number of people killed was 2,161 while 7,140 experienced non-fatal injuries [5]. According to the latest WHO data published in may 2014 Road Traffic Accidents 
Deaths in Ethiopia reached 15,015 or $2.50 \%$ of total deaths. The age adjusted Death Rate is 20.16 per 100,000 of population Ethiopia ranks 68 in the world by road traffic accidents [6].

In Ethiopia there are a few large cities and many small urban centers but because of the concentration of administration, economic activities, population and vehicles in these areas, the proportion of accident occurring in them is very significant. For example, in 1997/98 Addis Ababa accounted for 22 percent of all fatal accidents, 28 percent of serious and 68 percent of slight injuries of the country total accident [7].

Being the border town of the two countries (Ethiopia and Kenya) and its role as a cross-flight junction point to Borana, Guji it have all contributed a lot to rapid urbanization. Its location along the main roads to Kenya, the major trade sites within the borders of Ethiopia and Kenya can be considered as additional factors for the growth of the town and accidents.

Hence, due to the location and rapid urbanization as well as contraband trade in this region between years, the effect of road traffic accident is increasing. Meanwhile there are convincing indications that human health and economy has been significantly affected by road traffic accidents in Moyale town [8].

Thus, the researcher believes that it is essential to understand its likely impacts and develop sustainable coping

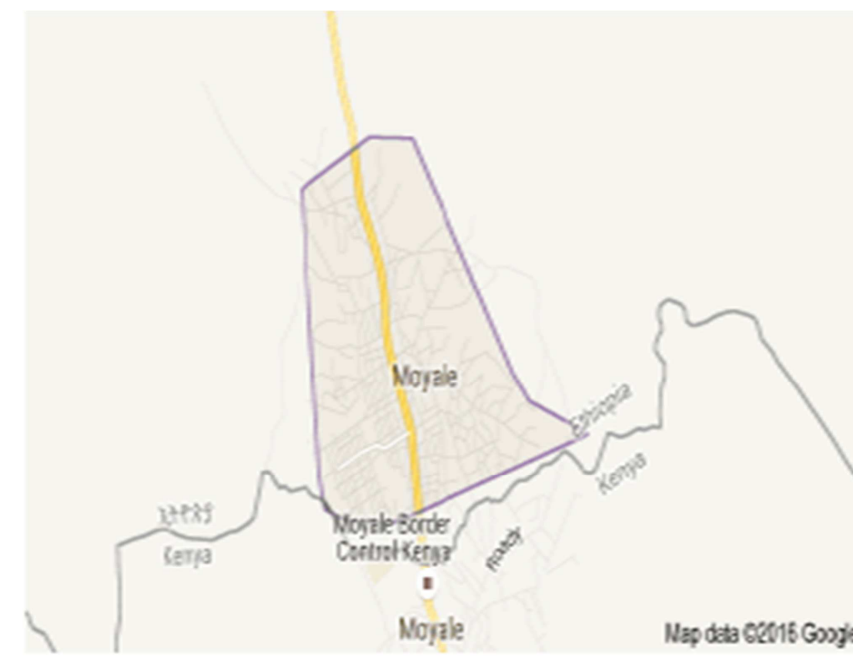

strategies for the community whose livelihoods would be affected by road traffic accidents. Identifying the implications of these accidents is also critically important to all stakeholders in the study area. Therefore, the writer focused to analyze road traffic accident in case of Moyale town.

\section{Methodology}

\subsection{Description of the Study Area}

The proposed study was carried out in Moyale town of Oromia regional state of Ethiopia. Moyale is a market town located on the border of Ethiopia and Kenya, which is split between the two countries: the larger portion is in Ethiopia (in the Oromia Region), and the smaller is in Marsabit Country, Kenya (the former capital of the defunct Moyale District). There are four disputed locations within the area of Moyale between the Somali and Oromo regions. Moyale is the main border post on the Nairobi -Addis Ababa road, lying north of the Dide Galgelu Desert. It is known for its traditional architecture.

Moyale has 34 kilometers of dry-weather and 55 allweather road, for an average road density of 5.71 kilometers per 1000 square kilometers. About $3.8 \%$ of the rural and $39.7 \%$ of the urban population has access to drinking water [9].

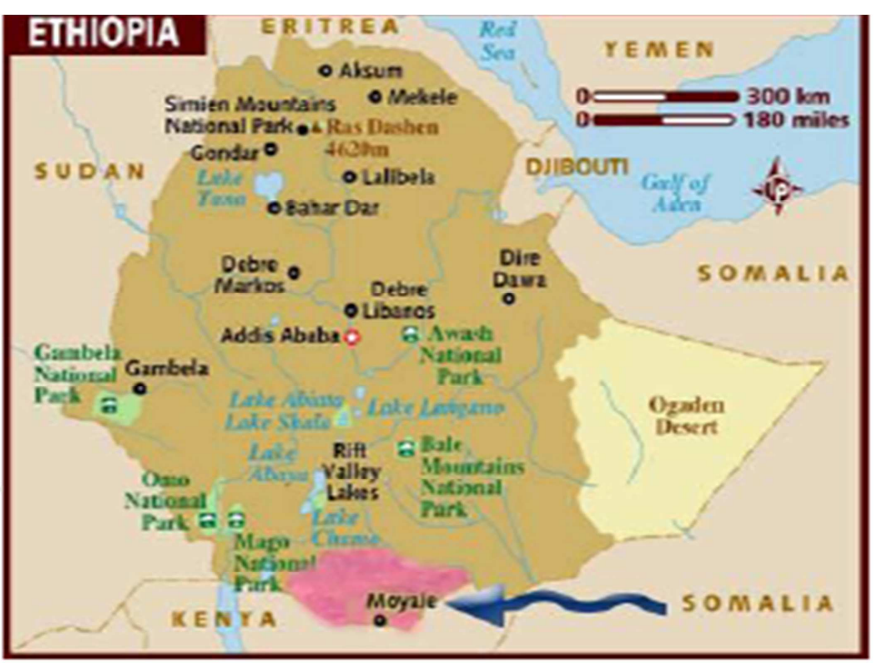

Figure 1. Map of the study area.

\subsection{Research Design}

A cross-sectional descriptive survey method was conducted during 0ctober and November 2016. For the purpose of this study, both quantitative and qualitative research approach were employed. Because, the combination of the two research approach gives better interpretation as the information missed by one might be captured by the other and thus an enhanced and integrated result may emerge from the analysis. The quantitative data was employed by closed ended questions and qualitative data was employed in openended questions, Interviews and personal observation.

\subsection{Sampling Technique}

The choice of sample design depends on the type of the research and the kind of conclusion that the researcher like to draw from the study. There are two Kebeles which the study area has. The sampling techniques of this research were both probability and non probability sampling techniques. After selecting both kebeles found in the city, probability proportionate to their respective household number was distributed. To select 191 respondents systematic sampling by selecting every $39^{\text {th }}$ values households was conducted and three from Government officials, three victim from Moyale 
hospital, four traffic police, two transport experts, and eight drivers' totally twenty interviewers were purposely selected to gather in depth interview data.
The following table describes the sampling technique that was used by the researcher.

Table 1. Sampling procedure for Household survey.

\begin{tabular}{llll}
\hline No & Name of kebeles & Number of households in kebeles & Sample frame \\
\hline 1 & kebele-01 & $(3,705 \times 191) / 7,450$ & 95 \\
2 & kebele-02 & $(3,744 \times 191) / 7,450$ & 96 \\
& Total & 7,450 & 191 \\
\hline
\end{tabular}

Source: Compiled by researcher (2016G).

Table 2. Sampling procedure for interview.

\begin{tabular}{llll}
\hline No & Respondents & Sample size & Sampling method \\
\hline 1 & Transport experts & Purposive & Purposive \\
2 & Government officials & 3 & Purposive \\
3 & Traffic police & 4 & Purposive \\
4 & Victims from Moyale hospital & 3 & Purposive \\
5 & Drivers & 8 & 20 \\
& Total & & \\
\hline
\end{tabular}

Sources: Compiled by researcher (2016 G.C)

\subsection{Data Analysis and Presentation}

Data were collected through structured questionnaires, interviews and field observation from both qualitative and quantitative category. Both primary and secondary data were analyzed by using SPSS, Microsoft Excel such as frequency distribution tables, averages, percentages and ratios. These were later interpreted by using tables, graphs, bar charts and pie charts.

\subsection{Data Quality Control}

The researcher prepared self-checking questions, inspection and continued monitoring of enumerators during household survey. Then the collected data were safely organized, coded and input into Microsoft excel and SPSS as per its analytical need. Then it was checked before analytical operation has been run.

Therefore the researcher investigated and described the study topic by using valid, accurate and reliable data in order to achieve the objectives of the study and to have decision makers and other researcher's confidence and rely up on the data. Hence, the researcher measured the data quality in terms of validity, reliability and practicability.

\section{Results and Discussion}

Road traffic accident patterns that exists in Moyale town

\subsection{Extent and Trends of Road Accidents in Moyale Town, 2012-2016 G.C}

As shown in the Table 6 below, Secondary data gained from Moyale town police station revealed that road traffic accidents assumed to be really bad in the town of Moyale. Traffic police statistics greatly underestimated the true extent of nonfatal accident situations (only fatality accidents are relatively well- reported). In between 2012 and 2016, for example, 579 Heavy and Light injury, road transport related injuries were registered by Borena zone police office. These people received medical treatment as inpatient and outpatient in the town hospital, health center and clinics. But in the same years the Moyale town traffic police registered only 76 road injury accidents. These are indications that more accidents go unreported, and that the statistics compiled are not always reliable. This data also revealed that, the accidents and property damage is increasing from year to year.

Table 6. The Extent and Trends of Road Accidents in Moyale Town, 2012-2016 G.C.

\begin{tabular}{|c|c|c|c|c|c|c|c|c|c|c|c|c|c|c|c|c|}
\hline \multirow{3}{*}{ S/no } & \multirow{3}{*}{ Types of accident } & \multicolumn{15}{|c|}{ Year reference (2012-2016) G.C Victims by sex } \\
\hline & & \multicolumn{3}{|c|}{2012} & \multicolumn{3}{|c|}{2013} & \multicolumn{3}{|c|}{2014} & \multicolumn{3}{|c|}{2015} & \multicolumn{3}{|c|}{2016} \\
\hline & & M & $\mathbf{F}$ & Total & $\mathbf{M}$ & $\mathbf{F}$ & Total & M & $\mathbf{F}$ & Total & M & $\mathbf{F}$ & total & M & $\mathbf{F}$ & Tottal \\
\hline 1 & Fatal injury & 1 & 0 & 1 & 1 & 1 & 2 & 0 & 2 & 2 & 2 & 1 & 3 & 4 & 3 & 7 \\
\hline 2 & Heavy injury & 11 & 9 & 20 & 14 & 12 & 26 & 18 & 13 & 31 & 16 & 18 & 34 & 19 & 26 & 45 \\
\hline 3 & Light injury & 31 & 22 & 53 & 51 & 37 & 88 & 47 & 42 & 89 & 60 & 35 & 95 & 71 & 27 & 98 \\
\hline 4 & Property damage & \multicolumn{3}{|c|}{152,300 birr } & \multicolumn{3}{|c|}{42,820 birr } & \multicolumn{3}{|c|}{155,650 birr } & \multicolumn{3}{|c|}{152,200 birr } & \multicolumn{3}{|c|}{306,600 birr } \\
\hline
\end{tabular}

Source: Compiled by Borena zone police office (2016 G.C)

As shown in the Table 7, in an attempt to deduce the perception of respondents towards traffic safety problems in Moyale, a question was asked to the respondents "How do they perceive the level of road traffic accidents in Moyale".
The majority of respondents ( 88.5 percent) interviewed agree that the current accident problems are Big problem in Moyale. This shows that the level of perception of the problems experienced by respondents in the town is very 
high. In the same box in column 3, the majority of respondents interviewed (71.7 percent) replied that they faced or observed road traffic accidents one times in their trip of the town.
Regarding the interviewed drivers, out of those eight drivers who were interviewed 5 of them revealed that as they faced traffic accidents two and more times.

Table 7. Perceived level of traffic accidents in Moyale town.

\begin{tabular}{|c|c|c|c|c|c|c|}
\hline \multirow{4}{*}{$\begin{array}{l}\text { Questions } \\
\text { How you perceived the level of road } \\
\text { traffic accidents in your community? }\end{array}$} & \multicolumn{6}{|c|}{ Alternative responds } \\
\hline & \multicolumn{2}{|c|}{ Big problem } & \multicolumn{2}{|c|}{ Moderate problem } & \multicolumn{2}{|c|}{ Not a problem } \\
\hline & No & $\%$ & No & $\%$ & No & $\%$ \\
\hline & 169 & 88.5 & 19 & 9.9 & 3 & 1.6 \\
\hline \multirow{3}{*}{$\begin{array}{l}\text { Have you faced/observed traffic } \\
\text { accidents in your Journey? }\end{array}$} & Yes & & No & & & \\
\hline & No & $\%$ & No & $\%$ & & \\
\hline & 145 & 75.9 & 46 & 24.1 & & \\
\hline \multirow{3}{*}{$\begin{array}{l}\text { If you faced/observed accidents, how } \\
\text { many times? }\end{array}$} & One Times & & Two & & Thre & \\
\hline & No & $\%$ & No & $\%$ & No & $\%$ \\
\hline & 104 & 71.7 & 32 & 16.8 & 9 & 4.7 \\
\hline
\end{tabular}

Source: Compiled by Researcher from the Survey (2016 G.C)

Observation in Moyale showed that there are notable tendencies of respondents towards walking along vehicle roads and with their backs to traffic as well as riding motor cycle by two or three. When asked to indicate how frequent do a respondents has to leave the sidewalks and walk along roads, 8 ( 4 percent) indicated that they always do this, 52 (27 percent) indicated that they sometimes do this while $101(53$ percent) indicated that they rarely do this, others 30 (16 percent) indicated that they never do this. The demonstrated tendency of pedestrians to leave the sidewalks and walk along the roads increases the risk of a pedestrian being exposed to traffic accidents.
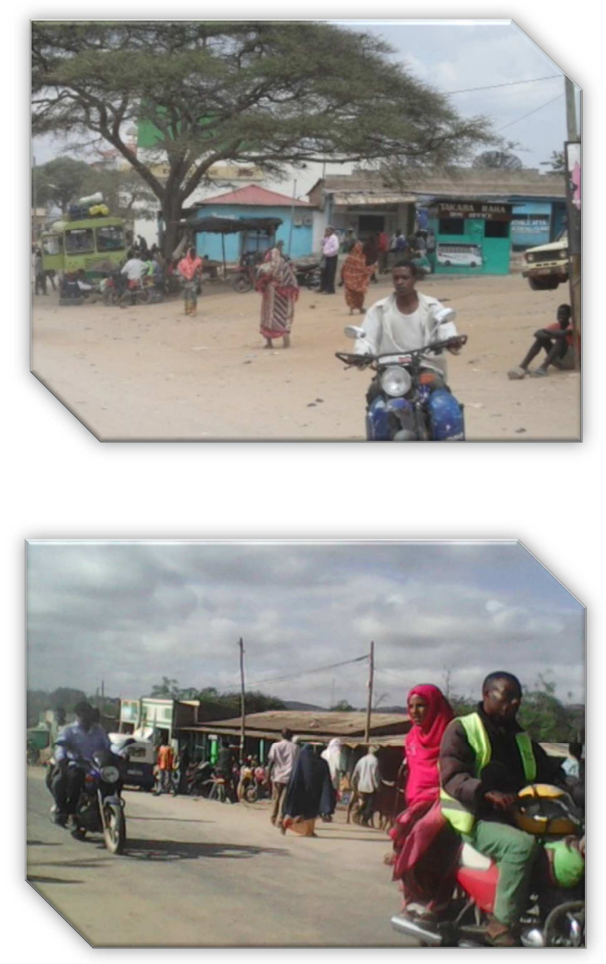

Figure 2. Road status in Moyale town and Riding style of motor in Moyale tow.

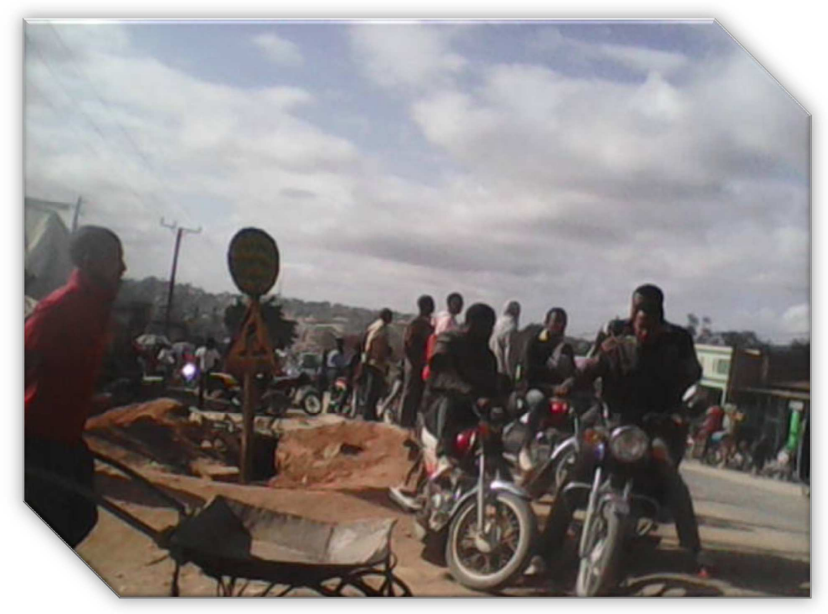

Figure 3. Motor Vehicle in Moyale town.

\subsection{The Major Causes of Road Accidents}

As shown in the Figure 4, respondents who were asked a question "which of the driver's error highly aggravated traffic accidents on the town roads"; of those who were asked 46 (24.1 percent) of them revealed as the high speed of vehicles are the most profound problem that endangers their safety when attempting to cross roads. The results also indicate that 52 (27.2 percent) of respondents perceive nonabidance of drivers to pedestrian's traffic rules as the first serious safety problem encountered while crossing the roads. Limited number of properly designed pedestrian crossing also accounts 52 (27.2 percent), lack of enforcement 41 (21.5 percent) and others are problems in their order of seriousness.

The interviewed drivers also revealed as the major causes of the traffic accidents are absence of segregated lane for pedestrians, poor road conditions, and absence of priorities given to vehicles by motor car drivers of which each of these accounts $25 \%$ responses of respondents and only one driver complain that negligence of pedestrians for vehicles. 


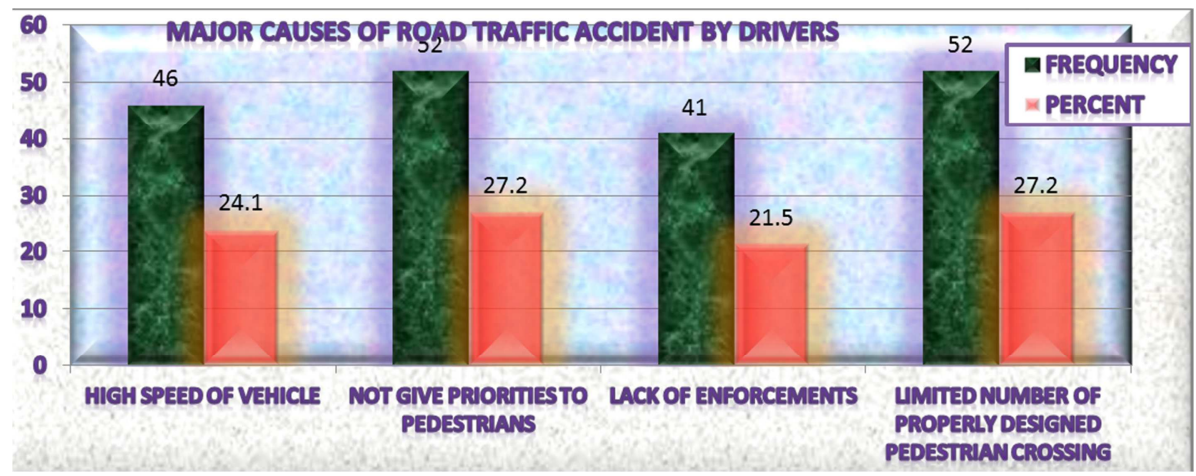

Source: Compiled by Researcher from the survey (2016 G.C)

Figure 4. Major Causes of Road Traffic Accidents in Moyale town.

As shown in the Figure 5, respondents were also asked how much they perceive traffic signs, signals, and road marks when they walk and cross the roads. For this question only 86 (45 percent) of all respondents indicated, as they perfectly understood. But the majority of respondents, 105 (55 percent) were not clearly aware of the traffic signs and road marks.

Regarding the interviewed drivers all of them revealed that they understood traffic signs, signals, and road marks.

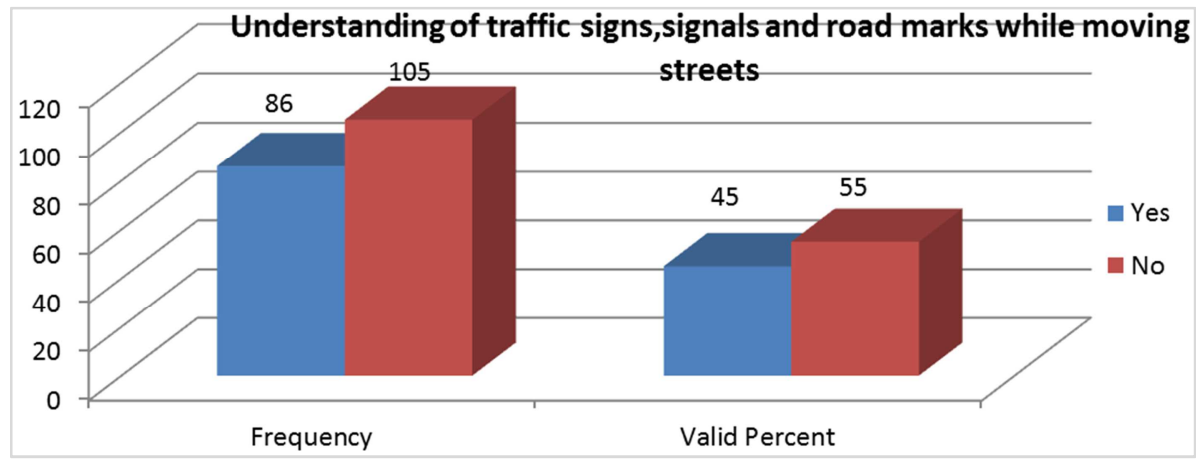

Source: Compiled by Researcher from the Questionnaires (2016 G.C)

Figure 5. Understanding of Traffic Signs, Signals and Road Marks while moving on the streets in Moyale town.

As shown in Figure 6, the majority of drivers interviewed (47.6 percent) of the total responded that they always give priorities to pedestrians, 52.4 percent sometimes give priority to pedestrians. However the majority of the surveyed drivers 84 percent highly criticized pedestrians' behavior in applying the laws and rules of traffic.

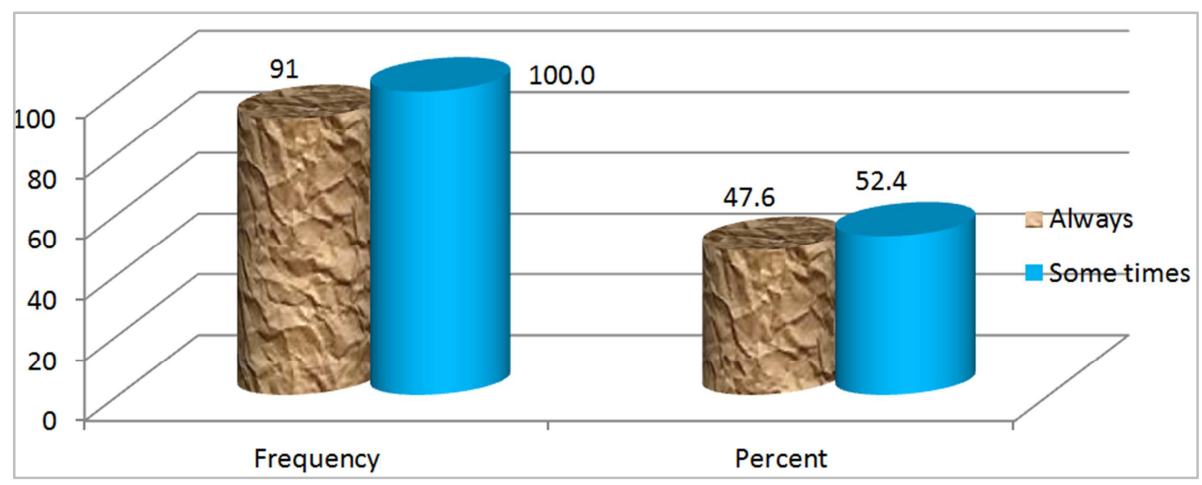

Source: Compiled by Researcher from the Questionnaires (2016 G.C)

Figure 6. Priorities Given to Vehicles as Required by Law in Moyale town.

As shown in Figure 7, Pedestrians were asked questions as to where they would usually cross main roads. Alternatives given were: at traffic light, at junctions, at any point, at midblock pedestrian crossing away from junctions. For this question the majority of the surveyed pedestrians, 112 (58.6 percent) have indicated that they would cross roads at any point, 75 (39.3 percent) at mid block pedestrian crossing away from junctions and 4 (2.1 percent) at junctions. This shows that about most of the pedestrians would tend to cross roads at any of the other unsafe points. This represents a dangerous crossing attitude that might lead to the occurrence of accidents. 


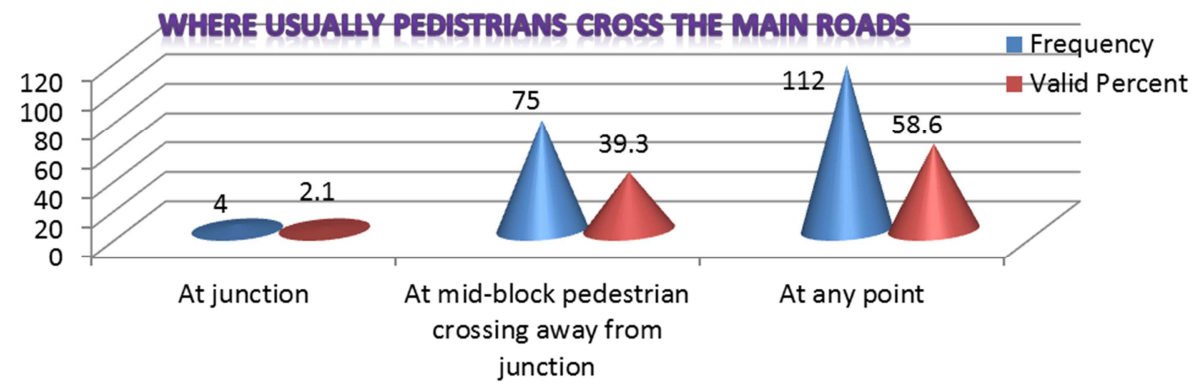

Source: Compiled by Researcher from the Questionnaires (2016G.C)

Figure 7. Road crossing Sites in Moyale town.

As shown in Figure 8, the severity of accidents occurring when pedestrians were crossing was higher. This figure confirms with to the result of the majority of the surveyed pedestrians, 164 (85.9 percent) indicated that crossing the roads in Moyale is difficult and only 27 (14.1 percent) of them revealed as crossing the main roads is easy in Moyale town.

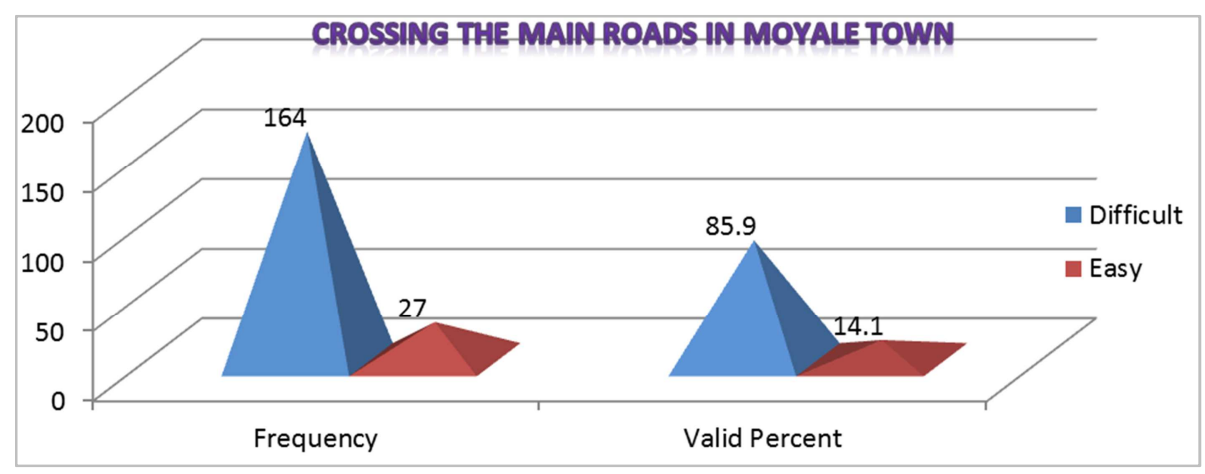

Source: Compiled by Researcher from the Questionnaires (2016 G.C)

Figure 8. Crossing the main roads in Moyale town.

As shown in the Table 8, the response of the respondents for the first question, 156 (81.7 percents) indicated that the presence of penalties some times for drivers for their law offensive, 18 (9.4 percent) them replied that as there is always penalties for those drivers who fail to maintain rules and regulations while, 17 (8.9 percent) of interviewed dwellers indicated that they did not see any penalties for law offensive drivers. Concerning the second question in the below box, large number of respondents interviewed criticize the current system of penalties taking by traffic police against offending drivers, 87 (45.8 percent) of all respondents were replied that the traffic police commitment to their duties are poor.

Table 8. Perceived level of penalties by drivers and commitment of traffic police in Moyale.

\begin{tabular}{|c|c|c|c|c|c|c|}
\hline $\begin{array}{l}\text { Are drivers failing to maintain traffic rules and regulations in the presence of } \\
\text { traffic police would be penalized for their law offensive? }\end{array}$ & $\begin{array}{l}\text { Always } \\
\text { No } \\
18\end{array}$ & $\begin{array}{l}\% \\
9.4\end{array}$ & $\begin{array}{l}\text { Some times } \\
\text { No } \\
156\end{array}$ & $\begin{array}{l}\% \\
81.7\end{array}$ & $\begin{array}{l}\text { Never } \\
\text { No } \\
17\end{array}$ & $\begin{array}{l}\% \\
8.9\end{array}$ \\
\hline How do you rate the traffic police Commitment to their duties? & $\begin{array}{l}\text { V. Good } \\
\text { No } \\
10\end{array}$ & $\begin{array}{l}\% \\
5\end{array}$ & $\begin{array}{l}\text { Good } \\
\text { No } \\
94\end{array}$ & $\begin{array}{l}\% \\
49.2\end{array}$ & $\begin{array}{l}\text { Poor } \\
\text { No } \\
87\end{array}$ & $\begin{array}{l}\% \\
45.8\end{array}$ \\
\hline
\end{tabular}

Source: Compiled by Researcher from the Questionnaires (2016 G.C)

For the first question in the Table 9, large proportion of respondents, and 85 (45.5 percent) did not get education about road traffic rules by concerned officials. For the second question the majority of respondents, 16 (15 percent) have indicated that they have learned how to deal with traffic by themselves and 41 (39 percent) through school. Also 11 (9 percent) have indicated the involvements of media (radio and television), and 22 (20.5 percent) of respondents have also indicated the involvements of traffic police; and the parent involvements accounted 15.5 percents. The below responses and result demonstrate the almost non-existence of any systematic official source for providing the necessary education, training and information related to traffic safety. Television and radio both have a wide coverage in town of Moyale.

Thus, essential mixed safety message can promote for influencing human behaviors and attitude. However, their broadcasting of road safety education is still limited and not gained great attention. 
Table 9. Two interrelated questions were introduced to the pedestrians whether they gained education or not about road safety.

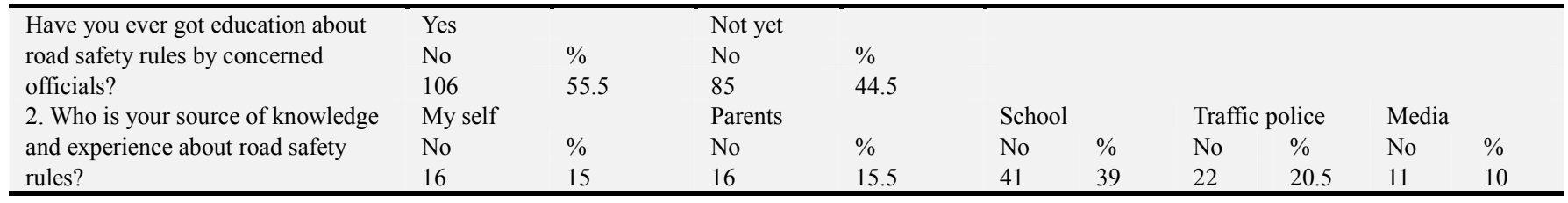

Source: Compiled by Researcher from the survey (2016 G.C)

From the trip purposes indicated in Figure 9, work trip purpose would be perceived as constituting the main part of pedestrian journey, 105 (55 Percent), business/ shopping trip selected 39 (20.4 percent), and recreational trip accounts 7 (3.7 percent), while walking for health services constitute 40
(20.9 percent ) of the journey which selected at the second level.

Regarding the interviewed drivers all of them revealed that the purpose of their trip is work Trip only.

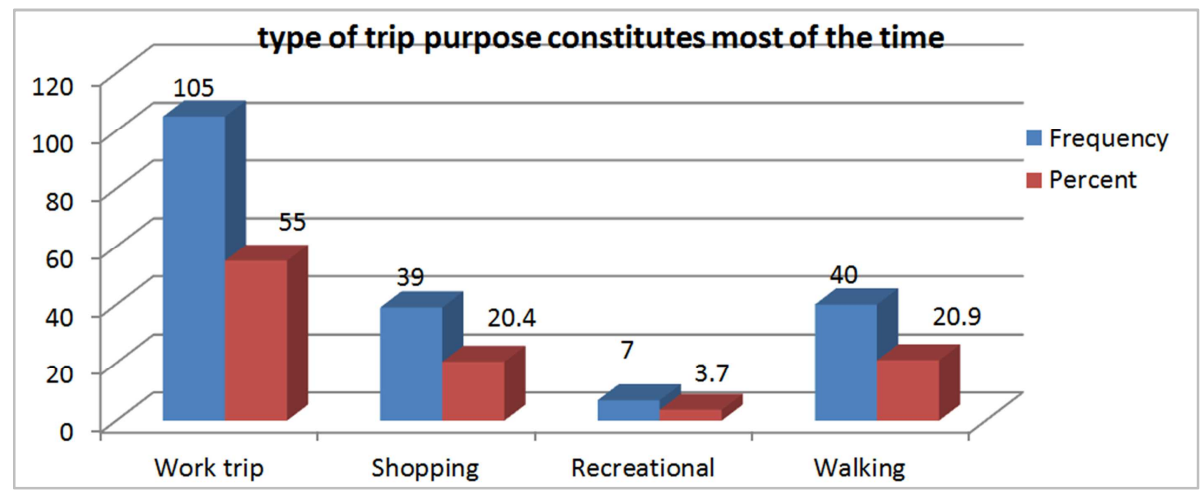

Source: Compiled by Researcher from the Questionnaires (2016 G.C)

Figure 9. Type of Trip Purpose Constitutes Most of the time.

As shown in Figure 10, Respondents that accounted about 77.5 per cent followed by drivers with 87.5 per cent revealed that the highest percentage of fatalities and injuries were highly that of motor vehicle with pedestrians, 14.7 percent of them said that the most prevailed collision is motor vehicles with motor vehicles and only 7.9 percent of the respondents said it is motor vehicle with static object.

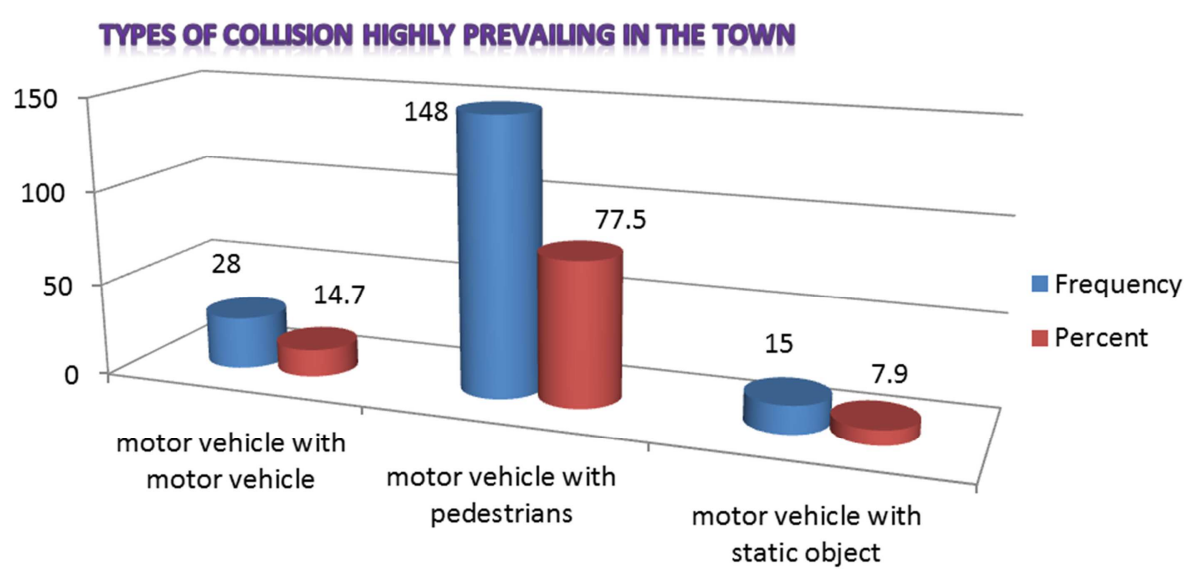

Source: Compiled by Researcher from the survey (2016 G.C)

Figure 10. Types of Collision highly prevailing in Moyale Town.

\subsection{Most Accident Vulnerable Class of Road Users in Terms of Sex and Age groups.}

The records in Figure 11 show that accidents involving youth contribute a high percentage of the total accidents in Moyale. Many factors could be raised to this accidents but the major one is inadequate education and training of youth on how to use the road safely and drive motor vehicles especially motor cycle which is highly prevalent in the town.

As shown in the Figure 11, 41.9 percent of respondents revealed as Most of the vulnerable groups in Moyale town were youth, 22 percent stated as Elders were affected, 13.6 of them were revealed as women were affected and only 9.4 percent of respondents said that Adults were vulnerable 
groups of traffic accidents in Moyale town.

The data obtained from the traffic police also indicated that more than 80 percent of injured youth were pedestrians and the rest 20 percent were most likely related to motor cyclists, and more than four- fifth ( 80 percent) of injured youth were in the age groups of 14-25 years.

Variations of Traffic Casualties by Sex and Age Groups

In Moyale, the road traffic accident risk for male population is by far higher than that of females. For example in between 2012-2016 female accidents accounted for only 42 percent of the whole casualties.

The distribution of road traffic accident victims varies with age, mainly depending on their amount of exposure and degree of safety awareness.

As can be seen in Figure 11, the road accident risk is very high among the male work- force (18-50) age group).

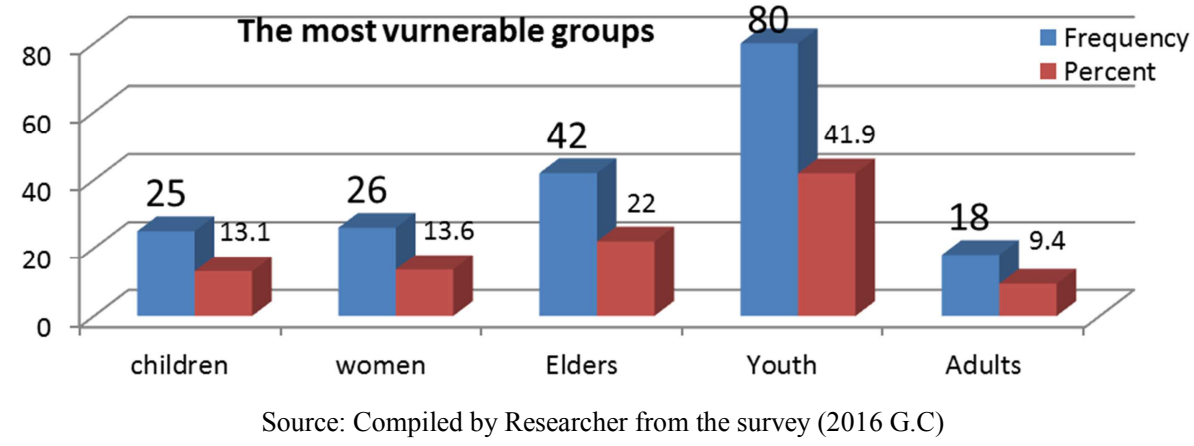

Figure 11. Most accident vulnerable class of road users in terms of sex and age groups in Moyale town.

\subsection{Socio-Economic Impacts That Have Been Incurred Due to Road Traffic Accidents}

The consequences of road traffic accidents have both social and economic impacts. One of the major economic impacts caused by road traffic accidents is damage on property.

\section{Socio-economic impact regestered in Moyale town}

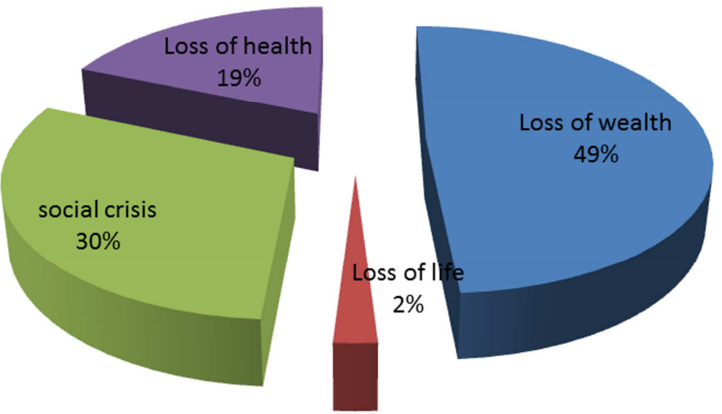

Source: Compiled by Researcher from the survey (2016 G.C)

Figure 12. Socio-economic impacts that have been incurred due to road traffic accidents.

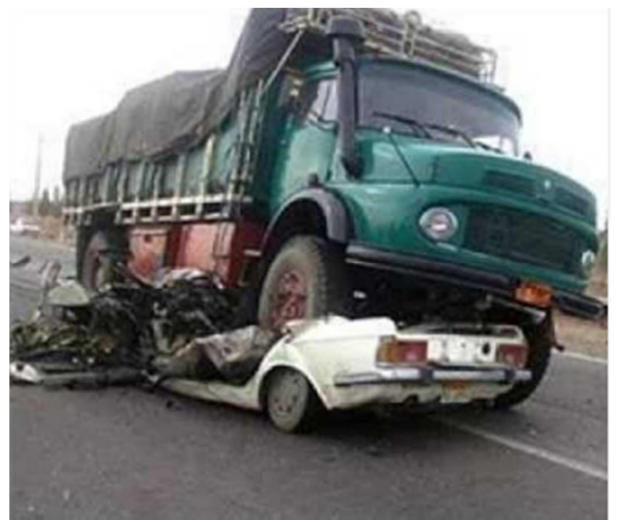

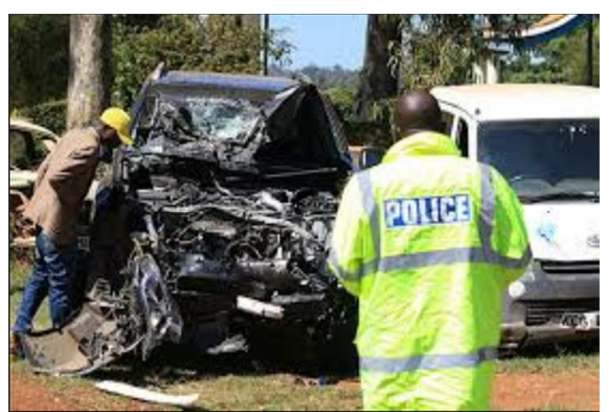

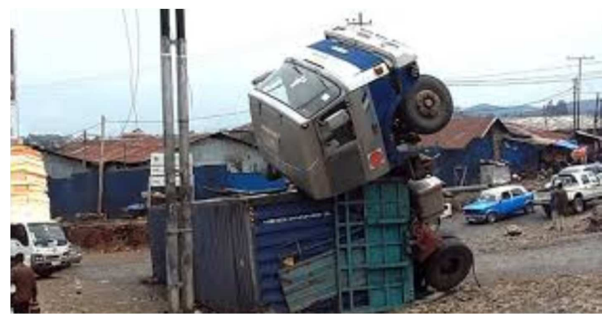

Figure 13. Damage on Property Accidents in and around Moyale town.

The main cost component in damage to property is the value represented by crashed vehicles. Property damage, however, also includes damage caused to objects inside the vehicles, such as cargo, and damage to objects outside the vehicles, such as, roadside furniture (sign posts, guardrails, etc.) and fixed property (fences, houses, etc.).

The amount of damage on property usually depends on the number of accidents. The higher the number of road traffic accidents the larger the damage on property.

As it can be seen from Table 10 below, the total damage on property accidents only estimated in birr in the years from 2012 to 2016; was around 809,570 birr. Looking at the distribution of wasted property within a year for the last 5 years, one can understand that a picture of huge sum of money is lost each year.

This implies that the percentage share of annual budgeted 
loss as a result of road accidents in the town of Moyale is high.

Table 10. Reported Damaged Property Accidents and Estimated Costs in Birr in Moyale.

\begin{tabular}{lll}
\hline Year & $\begin{array}{l}\text { Number of vehicle Damaged in } \\
\text { Accidents }\end{array}$ & Estimated cost (Birr) \\
\hline 2012 & 22 & 152,300 \\
2013 & 19 & 42,820 \\
2014 & 47 & 155,650 \\
2015 & 34 & 152,200 \\
2016 & 47 & 306,600 \\
Total & 169 & 809,570 \\
\hline
\end{tabular}

Source: Compiled by Moyale town police station (2016 G.C)

\section{Conclusions}

The road traffic accidents in Moyale were highest particularly on the main streets of schools, shopping centers, office areas and on older mixed residential roads with narrow right ways. These roads constitute 10 percent of the total road length of the town and account for more than 80 percent of the road accidents. Road facilities such as, safety guard police, reflectors, street lighting, appropriated road marking, traffic and direction signs, which improve safety on the road are either insufficient or totally absent in these streets.

Hence, the annual accident rate in Moyale for the last five years fluctuated between 150 and 597, or remained nearly constant with an average of 120 accidents per year. This rate is extremely high on the national road safety scenes which are attributable to high population number (increase in road users) and high traffic mixes.

The traffic accident data analysis in Moyale town indicated that most of the accidents are caused due to drivers not respecting pedestrian priority; over speeding; Poor skill and undisciplined behavior of drivers; Pedestrians not taking proper precautions; Over loaded or improperly loaded vehicles; Weak traffic law enforcement; Lack of proper emergency medical services; Poor vehicle conditions; and institutional and process related issues like, Weak Institutions \& Poor Coordination; Laxity in Enforcement and Poor Emergency and Rescue Services.

Regarding vulnerable road traffic accidents vary as socioeconomic characteristics of a nation (age group, sex, income level, etc). In moyale town road traffic accidents tend to strike males in the prime of life when they are likely to be at the peak of economic and social importance as household.

Again road traffic accidents more likely happen to people from all economic groups but more often to that of poor. When injured, the poor also have less chance of survival and full recovery.

Coming to socio-economic impacts that have been incurred in Moyale town, road traffic accidents appeared to cost about 0.98 percent of the town's budget per annum. In other word about one percent of the town wealth $(161,914$ Birr) per annum was lost as a result of road accidents.

Another serious health related consequences of road traffic accidents are mental health problems, which can have a substantial impact on the survivors of road traffic accidents and their families. The common disorders are Acute Stress Disorder (ASD), Post Traumatic Stress Disorders (PTSD), anxiety disorders, depression and mood disorders. Again High levels of anxiety, depression, irritability and mood disturbances are the most common psychological symptoms among victims' relatives with related to the shock of losing their close relatives or loved ones.

\section{Acknowledgements}

I am much obliged in thanking Mrs Fatuma Hamid for the financial, technical and moral support rendered during my studies in addition to Moyale town.

\section{References}

[1] Goswami, A \& Sonowal, R 2009, A statistical analysis of road traffic accidents in Dibrugarh City, Assam, India. Division of Epidemiology and Nutrition, Regional Medical Research Centre.

[2] Road Transport Authority, 2013, Highlights of road traffic accident in Ethiopia in 2003 [Cited 12 December 2013]; Available at: URL:http://www.rta.gov.et/ accident.htm.

[3] IRIN, 2011, Ethiopia: Government moves to address road accident toll, 2011 [Coted 1 April 2012]; Available at: URL:http://www.irinnewsorg/report/94165/3thiopgovernment-moves-to-address-road-accident-toll.

[4] Road Transport Authority, 2014, Various unpublished Reports, Various Year, Addis Ababa.

[5] United Nations. Case study: Road safety in Ethiopia, 2009 [Cited 23 August 2013]; Available at: URL: http://repository.uneca.org/bitstream/handle/10855/5250/bib. $\% 205641$.

[6] World Health Organization, 2014, World report on road traffic injury prevention. Geneva; WHO, 2014.

[7] Federal Traffic Police 2009-2013, Various unpublished Reports, Various Year, Addis Ababa.

[8] Girma Berhanu 2010, Effects of Road and Traffic Factors on Road Safety in Ethiopia, Trondheim, Norway.

[9] Moyale town communication Office (2015). Moyale town Profile, unpublished.

[10] Adogu, P, Ilika, AL \& Asuzu, AL 2009, Predictors of road traffic accident, road traffic injury and death among commercial motorcyclist in an urban area. p. 18(4).

[11] Alarming statistics on road accidents. (2015, may 26). Retrieved from http://www.nigeriabestforum.com/generaltopics/?p:44020.

[12] Alister, C, OBE \& B, Simon 2011, Licensed to Skill, England and Wales, Institute of Advanced Motorists Limited, pp. 17-22.

[13] Atubi, AO 2012, 'Determinants of road traffic accident occurrences in Lagos State: Some lessons for Nigeria', International Journal of Humanities and Social Science; 2(6):252-259. 
[14] Baldo, V 2013, 'Epidemiological aspect of traumatic brain injury in Northeast Italy', European Journal of Epidemiology, vol. 18: p. 1059-1063.

[15] Barrett, R 2009, 'National Urban and Town Road Safety Comparisons', in OECD (eds.). In Compendium of Papers on Second African Road Safety congress, Addis Ababa, 1620, October 1989; OECD, Norway.

[16] Berg, L 2013, Drinking and driving: intentions, attitudes and social norms of Swedish male drivers. Accident Anal Prev 2013, 25:289-296.

[17] Berhanu, Girma 2008, 'Causes of road traffic accidents and possible counter measures on addis ababa-shashemene roads', ILS Proceedings - The 19th Annual Conference. Addis Ababa: Addis Ababa University available at http://hdl.handle.net/123456789/1964.

[18] Blanchard, E \& Veazey, C 2011, mental disorders resulting from road traffic accidents. Current Opinion in Psychiatry. p. 143-147. Retrieved from http://ovidsp.tx.ovid.com.

[19] Central Statistical Authority 1994, 'Population and Housing Census of Ethiopia', CSAAddis Ababa, Vol.1, Part IV.

[20] Cummings, P, McKnight, B, Rivara, P\& Grossman, C 2012, Association of driver air bags with driver fatality, a matched cohort study, BMJ, 324:1119-1122.

[21] Eke, N 2011,'Road traffic accidents in developing world: who are liable?', Anil Aggrawal's Internet Journal of Forensic Medicine and Toxicology, 2(1).

[22] Federal Democratic Republic of Ethiopia: Police Commission Report 2015.

[23] Finch, J, Kompfner, P, Lockwood, R \& Maycock, G 2011, Speed limits and accidents Transport Research Laboratory, 2011.

[24] Garber N. Jand Hoel, L. A, 1999, Traffic and Highway Engineering. Thonson Publishing, USA.

[25] Gururaj, G 2014, Alcohol and road traffic injuries in South Asia: challenges for prevention, J Coll Phys Surg, Pakistan 2014, 14:713-718.

[26] Hassen, A, Godesso, A, Abebe, L \& Girma, E, Risky driving behaviors for road traffic accident among drivers in Gedeo Zone, Ethiopia. BMC Research Notes 2011; 4(535):1-6.

[27] Herbert, D. S 2009, Urban Development in Third world, Policy Guidelines, Praeger Publisher, New York.

[28] Hobbs, F. D 1999, Traffic Planning and Engineering, Pergamon press Oxford, England.

[29] Hutchinson, B. G 2004, Principles of Urban Transport Systems Planning, Script Book Campany, Washington D. C.
[30] Jacobs, G. D and Thomas, 2000, African Road Safety Final Report, FHWA, USA.

[31] Kothari, C. R, 2004, Research Methodology, Methods \& techniques, New Delhi, New Age International Publisher.

[32] Lum, H \& Reagan, JA 2005, Interactive Highway Safety Design Model: Accident Predictive Module , Public Roads, Federal Highway Administrat ion, , p. 59(2).

[33] Manuel, Kassaye, Sibhatu \& SGS , R D 2013, Road Traffic Accidents in Ethiopia.

[34] Mesganaw 2012, Patterns of mortality in public and private hospitals of Addis Ababa, Ethiopia.

[35] Mike, M 2009, Traffic crash victimizations of California children and teenagers by drinking over 21 drivers. Californian J Health Promotion, 7:92-101.

[36] Naci, H 2009, Chisholm, D \& Baker, T: Distribution of road traffic deaths by road user group: a global comparison. Inj Prev, 15:55-59.

[37] Nantulya, VM \& Reich, MR 2012, The neglected epidemic: Road traffic injuries in developing countries BMJ ; 324; 11391141.

[38] Odero, W, Garner, P \& Zwi, A 2007, Road traffic injuries in developing countries. a comprehensive review of epidemiological studies; Tropical Medicine \& International Health, pp. 2(5):445-460.

[39] Peden, M, Scurfield, R \& Sleet, D 2004, World report on road traffic injury prevention.

[40] Singh, A, Bhardwai, A, Pathak, R \& Ahluwalia, SK 2011, 'An epidemiological study of road traffic accident cases at a tertiary care hospital in rural Haryana', Indian Journal of Community Health 2011; 23 (2):53-55.

[41] Transport Research Laboratory 2000, Towards Safer Roads in Developing countries: A Guide for Planners and Engineers, TRL Overseas Development Administration, UK.

[42] World Health Organization, 2009, Global status on road safety: Time for action. Geneva; WHO, 2009.

[43] World Health Organization, 2013, Global status on road safety: Time for action, Geneva.

[44] Yared, D 2012, The Effects of Road Traffic Accidents in Addis Ababa City Administration: Cherkos Sub city, Unpublished.

[45] Yilma, B, Million, T \& Luce, T 2010, Motor vehicle accident and fatality surveillance Addis Ababa from 2000-2009 Addis Ababa.

[46] Zhu, M, Cummings, P, Chu, H \& Xiang, H 2008, Urban and rural variation in walking patterns and pedestrian crashes. Injury Prevention; 14; 377-380. 